\title{
The Korean Vacuum Society (KVS)
}

\author{
Il Ki HAN
}

General Secretary, Korean Vacuum Society

The Korean Vacuum Society (KVS) was established in September 1991 with 80 founding members. The objectives of the Society are to promote vacuum science, technology, and their applications, and to support the development of vacuum and its related fields including the semiconductor industry in Korea. In 2000 the Korean Vacuum Industry Association (KVIA) was also established to promote the Korean Vacuum Industry, and to support KVS.

In 2009 the membership of the society has reached to about 2,000 . Approximately $70 \%$ of these members are in universities, $20 \%$ in research institutions, and $10 \%$ in industry. These members represent a wide range of disciplines and fields including Physics, Chemistry, Electronics, Electrical Engineering, Metallurgy, Material Sciences, Mechanical, Nuclear, Life Science, Semiconductors, Electroluminescence, Vacuum, and others.

The society is administered by a General Assembly and a Board of Directors. There are five Executive Secretaries covering the domains of General Affairs, Publications, Treasury, Business, and Public Relations. The society has six Technical Divisions including Surface Science, Vacuum Technology, Plasma \& Display, Semiconductor \& Thin-film, Nano-technology, and Energy Science. Other activities are administered through four committees, namely a Fellows Committee, an Editorial Committee, a KVS-Industry Relations Committee, and an Awards/Honors/Scholarship Committee.

KVS has established and maintained many international relationships. In November 1991 KVS signed a Cooperative Relationship Memorandum with the American Vacuum Society (AVS). In October 1992 the society became a member of IUVSTA. Between 1992 and 1993 KVS established cooperative relationships with the Vacuum Society of Japan, the Japan Vacuum Industry Association, the Chinese Vacuum Society, and the Taiwan Vacuum Society. Since 1993, a number of conferences have been organized with international partners including Korean-Japan Vacuum Microelectronics Symposium in Seoul, Korean-Japan Symposium on Control of Semiconductor Interfaces, Korean-Japan CVD Symposium in Taegu, Korean-China Thin Films Symposium (held yearly), International Compound Semiconductor Symposium, Korea-Japan Symposium on Surface Analysis, and International Nanoscale Surface Science Symposium. In 2006 KVS hosted IUVSTA Special Symposium \& Highlight Seminar and the 100th IUVSTA Executive Council Meeting: ECM-100 in Seoul.

Other activities and services include: a 2-day Annual General Meeting; two 2-day Annual Symposia in February and August; survey, information collection and exchange; supports of international symposia, joint research and overseas meetings; encouragement of Vacuum Industry-Academy cooperation; recommendation of vacuum related policies to government; and vacuum standardization. Twice a year a Vacuum Equipment Exhibition is organized in conjunction with KVS meeting in February and August. About 30 to 40 companies used to contribute to these activities.

Every year a Short School (of two days) on Vacuum is presented and this leads to the presentation of a diploma. There are typically 80 students in attendance. In addition an Award is given to a Young Vacuum Scientist, at graduate school level, who attends and presents a talk at an IUVSTA, AVS or other Vacuum Meeting abroad.

During the period from 1991 to 2007, the Korean vacuum industry has grown by a factor of 5 in market scale. Recently Korean government has continuously supported lots of vacuum related projects under the supervision of KVS.

Current activities and more information can be found in the KVS homepage, http://www.kvs.or.kr. 